\title{
Renal sodium handling and neurohumoral systems in patients with cirrhosis in sitting posture: effects of spironolactone and water immersion*
}

\author{
A.L. Gerbes ${ }^{1}$, A. Pilz ${ }^{1}$, H. Wernze ${ }^{2}$, D. Jüngst ${ }^{1}$ \\ ${ }^{1}$ Medizinische Klinik II, Klinikum Großhadern, Ludwig-Maximilians-Universität München \\ ${ }^{2}$ Universitätsklinik Würzburg
}

Summary. Renal sodium handling, neurohumoral systems, and systemic hemodynamics were investigated under baseline conditions in sitting posture in 10 healthy subjects, 11 patients with cirrhosis without, and 10 patients with cirrhosis with ascites. Furthermore, the effects of head-out water immersion, 1-week spironolactone administration, or their combination was assessed in the two groups of patients. Patients without ascites exhibited a significant increase in plasma norepinephrine concentration and a tendency toward an increase in plasma aldosterone concentration. Patients with ascites had a significantly lower mean arterial blood pressure despite significant reduction of urinary sodium excretion and fractional sodium excretion as well as an increase of plasma renin activity, plasma aldosterone, and norepinephrine concentration. In patients with ascites, the increase in renal sodium excretion and fractional sodium excretion following water immersion or spironolactone was clearly augmented by the combination of the two maneuvers. The same pattern was observed in patients without ascites. Our findings (a) underscore the importance of studying hemodynamics, renal function, and neurohumoral systems also in upright posture, (b) suggest a role of sympatico-adrenergic activation and proximal sodium retention in preascitic patients, and (c) are compatible with the vasodilation hypothesis of ascites formation.

Key words: Ascites formation - Peripheral vasodilation - Proximal tubular sodium retention - Liver cirrhosis

New concepts have recently been introduced in the understanding of the pathophysiology of ascites

* Dedicated to Prof. Dr. G. Paumgartner on the occasion of his 60th birthday formation and renal sodium retention in cirrhosis of the liver (for review see [8]). The seeming contradiction of a reduced centrally effective blood volume in the presence of an augmented total blood volume in cirrhosis has lately been explained by peripheral arterial vasodilation [14]. Compensation of peripheral vasodilation in patients with cirrhosis without ascites may be achieved by total hypervolemia [1]. The latter may result from renal sodium retention due to activation of sodium-retaining neurohumoral systems. This activation is generally believed to contribute to ascites formation in patients with decompensated cirrhosis [2, $3,8]$. In patients without ascites, however, inconsistent findings have been reported regarding renal sodium handling and activation of the renin-aldosterone system. This may be due in part to the fact that patients have usually been investigated in the supine position where there may be no central underfilling whereas subjects normally spend twothirds of a regular day in the upright position [1].

Therefore it seemed useful to investigate subjects in the upright position and also to apply a maneuver inducing central volume expansion by intravascular fluid shifting, namely head-out water immersion [5, 7]. Other groups as well as our own have previously demonstrated the usefulness of water immersion for investigating neurohumoral systems and renal sodium handling $[5,7,9]$. Water immersion, by increasing distal tubular sodium delivery [5], may also elucidate the role of proximal tubular sodium retention, thought to be important particularly in patients with ascites [13]. We also studied the effects of the aldosterone antagonist spironolactone, acting at the distal tubule. Therefore the aim of this study was to compare - in cirrhosis with and without ascites in upright posture - systemic hemodynamics, renal sodium handling, the renin-aldosterone system, and plasma norepinephrine as an indicator of sympathetic nervous activity contributing to proximal tubular so- 
dium retention. The effect of head-out water immersion or spironolactone administration or their combination was investigated.

\section{Patients and methods}

Ten healthy subjects aged 40-65 years (mean $48 \pm$ 3 ) and 21 patients with cirrhosis, 11 without ascites $(61 \pm 2$ years) and 10 with ascites (56 \pm 3 years), were investigated after informed consent had been obtained. The protocol was approved by the Ethics Committee of the Faculty of Medicine, University of Munich. The subjects showed no evidence of cardiovascular, renal, pulmonary, or endocrine diseases. All subjects were prohibited alcohol, tobacco, tee, and coffee on the day before and during the experiment and were on a hospital diet containing approximately $150 \mathrm{mEq}$ sodium per day. The diagnosis of cirrhosis was established by biopsy and clinical and laboratory data. In 11 patients no ascites was detected by abdominal ultrasound. The etiology of cirrhosis was alcoholic in six, posthepatitic in four, and cryptogenic in one; the Child-Pugh classification $[12,15]$ was $\mathrm{A} / \mathrm{B}$ in nine/ two of these patients. Ten patients suffered from ascites as confirmed by abdominal ultrasound. The Child-Pugh classification was $\mathrm{B} / \mathrm{C}$ in six/four of them; the etiology of cirrhosis was alcoholic in six, posthepatitic in two, and cryptogenic in two patients. Both groups of patients were studied without diuretic treatment for 1 week, as reported earlier [9], and again following 1 week of spironolactone ( $200 \mathrm{mg}$ orally per day). Controls were investigated only in baseline conditions.

In the morning after complete emptying of the bladder an intravenous catheter was placed in a peripheral vein, patients drank $400 \mathrm{ml}$ water and assumed a sitting position. After $1 \mathrm{~h}$ the patients were immersed to the neck into thermoneutral water $\left(34.5 \pm 0.2^{\circ} \mathrm{C}\right)$ for $1 \mathrm{~h}$, maintaining the same sitting position. Patients were told to empty the bladder following the preimmersion and the immersion periods. Blood pressure and heart rate were monitored, and blood samples were collected before and after $1 \mathrm{~h}$ of immersion.

Urine was analyzed for sodium by flame photometry and for creatinine (Jaffe's reaction). Plasma renin activity was measured as described previously [16]. Plasma aldosterone concentration was determined with a commercial kit (Diagnostic Products, Los Angeles, USA). Plasma norepinephrine was determined radioenzymatically by a modified Peuler-Johnson method $[11,17]$. Fractional sodium excretion was calculated by standard formulas. Mean arterial pressure was calculated as the sum of diastolic pressure and one-third of the difference between systolic and diastolic pressure. Data are presented as mean and standard error. The random distribution of data was tested by the Kolmogorov-Smirnoff test. Statistical evaluation of randomly distributed data was performed by the unpaired $t$ test between groups and by paired $t$ test within groups. Nonrandomly distributed data were analyzed by Mann-Whitney test between groups and by Wilcoxon test within groups. A $P$ value of 0.05 or less was considered statistically significant.

\section{Results}

Comparison of baseline values without diuretics of both groups of patients with a group of healthy controls of similar age is shown in Table 1. Patients with decompensated cirrhosis exhibited a decreased mean arterial blood pressure despite an increase in heart rate, plasma renin activity, plasma aldosterone concentration, and plasma norepinephrine concentration, resulting in a reduction in urinary sodium excretion and fractional sodium excretion. Patients without ascites, not differing from controls in blood pressure or heart rate, showed a significant elevation in plasma norepinephrine concentration and a nonsignificant tendency towards increased plasma renin activity and plasma aldosterone concentration and a trend toward decreased renal sodium excretion and fractional sodium excretion.

Patients with as compared to patients without ascites exhibited a decrease in mean arterial pressure despite a further activation of sodium-retaining hormones and an increased heart rate (Table 2). Spironolactone administration clearly augmented urinary sodium excretion and fractional sodium excretion in decompensated patients without affecting the hemodynamics or the neurohumoral systems investigated. The renal effect of spironolactone was less marked in patients without ascites, who exhibited a trend toward activation of the renin-aldosterone and sympaticoadrenergic systems, almost reaching the level of patients with ascites. Water immersion reduced the activation of neurohumoral systems in both groups of patients, without the concomitant increase in sodium excretion reaching the level of statistical significance. Interestingly, the combination of spironolactone and water immersion significantly increased urinary sodium excretion and fractional sodium excretion not only in patients with ascites but also in those without ascites. 
Table 1. Baseline hemodynamics, hormonal, and renal parameters in controls and in patients without and in patients without ascites, in sitting posture

\begin{tabular}{|c|c|c|c|}
\hline & $\begin{array}{l}\text { Controls } \\
(n=10)\end{array}$ & $\begin{array}{l}\text { Patients without } \\
\text { ascites } \\
(n=11)\end{array}$ & $\begin{array}{l}\text { Patients with } \\
\text { ascites } \\
(n=10)\end{array}$ \\
\hline $\begin{array}{l}\text { Mean arterial pressure } \\
\quad(\mathrm{mm} \mathrm{Hg})\end{array}$ & $86 \pm 2$ & $85 \pm 3$ & $78 \pm 3^{*}$ \\
\hline Heart rate $(\min / 1)$ & $71 \pm 2$ & $74 \pm 2$ & $83 \pm 3 *, * *$ \\
\hline $\begin{array}{l}\text { Plasma renin activity } \\
\text { (ng Al/ml per hour) }\end{array}$ & $6 \pm 2$ & $9 \pm 3$ & $29 \pm 9 *$ \\
\hline $\begin{array}{l}\text { Plasma aldosterone } \\
\text { concentration }(\mathrm{ng} / 100 \mathrm{ml})\end{array}$ & $13 \pm 3$ & $38 \pm 11$ & $64 \pm 20^{*}$ \\
\hline $\begin{array}{l}\text { Plasma norepinephrine } \\
\text { concentration }(\mathrm{pg} / \mathrm{ml})\end{array}$ & $227 \pm 23$ & $430 \pm 70^{*}$ & $705 \pm 106^{*}$ \\
\hline $\begin{array}{l}\text { Urinary sodium excretion } \\
(\mu \mathrm{mol} / \mathrm{min})\end{array}$ & $105 \pm 24$ & $74 \pm 15$ & $28 \pm 11 * * *$ \\
\hline $\begin{array}{l}\text { Fractional sodium } \\
\text { excretion }(\%)\end{array}$ & $0.8 \pm 0.2$ & $0.6 \pm 0.1$ & $0.2 \pm 0.1^{*, * *}$ \\
\hline
\end{tabular}

* $P<0.05$ versus controls, ${ }^{* *} P<0.05$ versus patients without ascites

Table 2. Effects of 1-week spironolactone administration (200 mg orally per day) or 1-h head-out water immersion or combination of both maneuvers in patients without and in patients with ascites

\begin{tabular}{|c|c|c|c|c|c|}
\hline & & \multicolumn{2}{|c|}{ Patients without ascites $(n=11)$} & \multicolumn{2}{|c|}{ Patients with ascites $(n=10)$} \\
\hline & & $\begin{array}{l}\text { Without } \\
\text { spironolactone }\end{array}$ & $\begin{array}{l}\text { With } \\
\text { spironolactone }\end{array}$ & $\begin{array}{l}\text { Without } \\
\text { spironolactone }\end{array}$ & $\begin{array}{l}\text { With } \\
\text { spironolactone }\end{array}$ \\
\hline \multirow{2}{*}{$\begin{array}{l}\text { Mean arterial pressure } \\
(\mathrm{mm} \mathrm{Hg})\end{array}$} & Baseline & $85 \pm 3$ & $85 \pm 3$ & $78 \pm 3^{*}$ & $78 \pm 3$ \\
\hline & Immersion & $81 \pm 3$ & $78 \pm 3^{* * * * * * *}$ & $72 \pm 3^{*} * *$ & $72 \pm 3 * * * * * *$ \\
\hline \multirow{2}{*}{ Heart rate $(\min / 1)$} & Baseline & $74 \pm 2$ & $80 \pm 3$ & $83 \pm 3 *$ & $80 \pm 2$ \\
\hline & Immersion & $77 \pm 3 * *$ & $76 \pm 3$ & $84 \pm 3$ & $79 \pm 3$ \\
\hline \multirow{2}{*}{$\begin{array}{l}\text { Plasma renin activity } \\
\text { (ng AI/ml per hour) }\end{array}$} & Baseline & $9 \pm 3$ & $28 \pm 13$ & $29 \pm 9 *$ & $26 \pm 6$ \\
\hline & Immersion & $5 \pm 2 * *$ & $12 \pm 5$ & $17 \pm 7^{* *}$ & $14 \pm 3 * *$ \\
\hline \multirow{2}{*}{$\begin{array}{l}\text { Plasma aldosterone con- } \\
\text { centration (ng/100 ml) }\end{array}$} & Baseline & $38 \pm 11$ & $74 \pm 13$ & $64 \pm 20$ & $43 \pm 9$ \\
\hline & Immersion & $27 \pm 9 * *$ & $39 \pm 6^{* *}$ & $49 \pm 19$ & $33 \pm 8 * * ; * * *$ \\
\hline \multirow{2}{*}{$\begin{array}{l}\text { Plasma norepinephrine } \\
\text { concentration }(\mathrm{pg} / \mathrm{ml})\end{array}$} & Baseline & $430 \pm 70$ & $530 \pm 65$ & $705 \pm 106$ & $657 \pm 90$ \\
\hline & Immersion & $320 \pm 69 * *$ & $360 \pm 49 * *$ & $512 \pm 80^{* *}$ & $521 \pm 78 * *$ \\
\hline \multirow{2}{*}{$\begin{array}{l}\text { Urinary sodium excretion } \\
(\mu \mathrm{mol} / \mathrm{min})\end{array}$} & Baseline & $74 \pm 15$ & $130 \pm 54$ & $28 \pm 11 *$ & $149 \pm 54 * * *$ \\
\hline & Immersion & $149 \pm 50$ & $170 \pm 28 * * * *$ & $71 \pm 28$ & $239 \pm 74 * * *, * * * *$ \\
\hline \multirow{2}{*}{$\begin{array}{l}\text { Fractional sodium } \\
\quad \text { excretion }(\%)\end{array}$} & Baseline & $0 . \overline{6} \pm 0.1$ & $0.8 \pm 0.2$ & $0.2 \pm 0.1 *$ & $1.8 \pm 0.7 * * *$ \\
\hline & Immersion & $0.9 \pm 0.3$ & $1.5 \pm 0.2 * *, * * * *$ & $0.4 \pm 0.1$ & $2.6 \pm 0.9 * * *, * * * *$ \\
\hline
\end{tabular}

$* P<0.05$ versus patients without ascites, $* * P<0.05$ versus before water immersion, $* * * P<0.05$ versus without spironolactone, **** $P<0.05$ versus before water immersion without spironolactone

\section{Discussion}

In the present investigation we studied systemic hemodynamics, neurohumoral systems, and renal sodium handling in patients with cirrhosis with and without ascites, extending a previous study [9]. Based on recent findings by Bernardi et al. [1] as well as on the obvious observation that humans spend about two-thirds of the day in upright position we used the sitting posture as basal condition. Patients without ascites compared to controls of similar age showed a significant elevation in plas- ma norepinephrine concentration as an indicator of sympathetic nervous system activity and a tendency toward an increased plasma aldosterone concentration. These neurohumoral changes may result in the observed trends toward renal sodium retention. Thus our findings are compatible with the recent suggestion by Bernardi et al. [1] that patients without ascites could compensate for dilatation of the splanchnic vascular bed through total hypervolemia. Furthermore, the increased sympaticoadrenergic activity may cause proximal tubular sodium retention in these patients, who are still 
in the state of compensation. This contention is supported by the results of the combination of water immersion and spironolactone. Patients with ascites showed an increase in sodium excretion and in fractional sodium excretion upon spironolactone or water immersion, and the effect of the combination of these maneuvers was clearly enhanced. Interestingly, patients without ascites showed the same pattern, especially regarding fractional sodium excretion. These findings suggest that sympathicoadrenergic activation and proximal sodium retention, known to be of major importance in patients with ascites $[2,4,6,10,13]$ may play a role even in preascitic patients.

In patients without ascites spironolactone administration tended to increase plasma renin activity and norepinephrine concentration, compatible with volume depletion following the spironolactone therapy. These patients reached renin, aldosterone, and norepinephrine concentrations similar to baseline values of untreated patients with ascites. In contrast to decompensated patients, however, they maintained their mean arterial pressure. Thus, the decrease in mean arterial pressure despite further activation of sodium-retaining hormones and increased heart rate in patients with ascites suggests further vasodilation in these decompensated patients.

Our findings underscore the importance of studying hemodynamics, renal function, and neurohumoral systems in cirrhosis in the upright posture. Our observations are compatible with the vasodilation hypothesis and suggest a continuous development from healthy subjects via the state of compensation toward patients with ascites: activation of sodium-retaining neurohumoral systems, decrease in mean arterial pressure despite an increase of heart rate and renal sodium retention.

Acknowledgements. This research was supported by the Deutsche Forschungsgemeinschaft (Ge 576). T. Koberling is thanked for the preparation of the manuscript.

\section{References}

1. Bernardi M, Di Marco C, Trevisani F, De Collibus C, Fornalè L, Baraldini M, Andreone P, Cursaro C, Zacá F, Ligabue A, Gasbarrini G (1992) Hemodynamic status of preascitic cirrhosis: an evaluation under steady state conditions and after postural change. Hepatology 16:341-346

2. Bichet DG, van Putten VJ, Schrier RW (1982) Potential role of increased sympathetic activity in impaired sodium and water excretion in cirrhotic patients. $\mathrm{N}$ Engl $\mathrm{J}$ Med 307:1552-1557

3. Bosch J, Arroyo V, Betriv A, Mas A, Rivera F, NavarroLopez F, Rodes J (1980) Hepatic hemodynamics and the renin-angiotensin-aldosterone system in cirrhosis. Gastroenterology 78:92-99

4. DiBona GF (1982) The function of renal nerves. Rev Physiol Biochem Pharmacol 94:75-181

5. Epstein M, Saruta T (1971) Effect of water immersion on renin-aldosterone and renal sodium handling in normal man. J Appl Physiol 31:368-374

6. Epstein M, Pins DS, Schneider N, Levinson R (1976) Determinants of deranged sodium and water homeostasis in decompensated cirrhosis. J Lab Clin Med 87:822-839

7. Gauer OH, Henry JP, Behn C (1970) The regulation of extracellular fluid volume. Annu Rev Physiol 1970:547-595

8. Gerbes AL (1991) Pathophysiology of ascites formation in cirrhosis of the liver. Hepatogastroenterology 38:360-364

9. Gerbes AL, Wernze H, Arendt RM, Riedel A, Sauerbruch T, Paumgartner G (1989) Atrial natriuretic factor and reninaldosterone in volume regulation of patients with circhosis. Hepatology 9: 417-422

10. Henriksen JH, Ring-Larsen H, Christensen NJ (1985) Circulating noradrenaline and central haemodynamics in patients with cirrhosis. Scand J Gastroenterol 20:1185-1190

11. Peuler JD, Johnson GA (1977) Simultaneous single isotope radioenzymatic assay of plasma norepinephrine, epinephrine and dopamine. Life Sci 21:625-636

12. Pugh RNH, Murray-Lyon IM, Dawson JL, Pietroni ML, Williams R (1973) Transsection of oesophagus for bleeding oesophageal varices. Br J Surg 60:646-649

13. Schölmerich J (1991) Aszites. Springer, Berlin Heidelberg New York

14. Schrier RW, Arroyo V, Bernardi M, Epstein M, Henriksen JH, Rodes J (1988) Peripheral arterial vasodilation hypothesis: a proposal for the initiation of renal sodium and water retention in cirrhosis. Hepatology 8:1151-1157

15. Terblanche J, Northover JMA, Bornman P, Kahn D, Silber W, Barbezat GO, Sellars S, Campbell JAH, Saunders SJ (1979) A prospective controlled trial of sclerotherapy in the long term management of patients after oesophageal variceal bleeding. Surg Gynecol Obstet 148:323--333

16. Wernze H, Spech HI, Müller G (1978) Studies on the activity of the renin-angiotensin-aldosterone system (RAAS) in patients with cirrhosis of the liver. Klin Wochenschr 36:389-397

17. Wernze H (1983) Endokrinologische Diagnostik des Hochdrucks. In: Kühn HA, Lasch HG (eds) Untersuchungsmethoden und Funktionsprüfungen in der Inneren Medizin. Thieme, Stuttgart, pp 110-123

Received: June 21, 1993

Returned for revision: July 12, 1993

Accepted: July 15, 1993

Priv.-Doz. Dr. A.L. Gerbes

Medizinische Klinik II

Klinikum Großhadern

Marchioninistrasse 15

D-81366 München

Germany 